\title{
STRUCTURAL FACTORS FOR A THIRD-GENERATION PORT: PLANNING TRANSPORT INTERVENTIONS IN GIOIA TAURO, ITALY
}

\author{
GIUSEPPE MUSOLINO ${ }^{1} \&$ GIOVANNA CHILÀ ${ }^{2}$ \\ ${ }^{1}$ Dipartimento di Ingegneria dell'Informazione, delle Infrastrutture e dell'Energia Sostenibile, \\ Università Mediterranea di Reggio Calabria, Italy \\ ${ }^{2}$ Environment and Public Works, Municipality of Motta San Giovanni, Italy
}

\begin{abstract}
Ports can be classified into different categories, or generations, according to the definitions of UNCTAD. Third-generation ports emerged in the last decades of the 20th century, principally due to world-wide large scale containerization and inter-modalism combined with the growing requirements of the international trade. Ports turned into integrated transport centres and logistic platforms for international trade. The aims of this paper are to: (a) analyse the current conditions of Gioia Tauro port, in the context of Calabria Region (Italy); (b) propose strategic development directions and transport interventions towards a third generation port. Scenario and planned interventions in the port of Gioia Tauro are identified in the Regional Transport Plan of Calabria and in the strategic report of the Integrated Logistic Area (ALI) of Gioia Tauro. The defined scenario aims to achieve the objectives to strength the existing transhipment activities and to support the development of new port-related activities in the hinterland area. The infrastructural interventions aim to connect the port with the European networks and the access to/from Calabria Region. The interventions concern both the expansion of the port infrastructures, on the sea-side; and the increase of the railway and road infrastructures, on the land-side.
\end{abstract}

Keywords: third generation port, general logistics, infrastructures, Gioia Tauro port area.

\section{INTRODUCTION}

From ancient times ports were the gate for the exchange of freight and people. The evolution of ports may be described according to the concept of generation (see [1]-[3], and the references included). The first ports were built close to the cities. The port-city was the dominant model for centuries and these ports are considered as first-generation ports. During the industrial revolution of the 20th century, some new ports were built close to industrial areas, to support the supply of raw materials and final products of industrial plants. These ports are considered as the second-generation ports.

Third generation ports emerged after 1980s, principally due to world-wide large scale diffusion of container, combined with the growing requirements of the international trade. The ports have been turning into integrated transport centres and logistic platforms for international trade. From the economic point of view, third-generation ports increase added value of goods that transit through them, but due also to the manipulations that are placed in the goods.

The aim of this paper is to analyse current conditions of Gioia Tauro port, in the context of Calabria Region. Then, strategic development directions towards a third generation port are proposed, with a focus on general logistics (see [4], [5]). The transhipment activities of port of Gioia Tauro in the container market must be consolidated and strengthened, also through the full operation of the existing gateway, and of specific node interventions, supported by research and operational applications. The infrastructural interventions in Gioia Tauro port must guarantee the development of European networks and access to/from the Calabria Region. The European networks and corridors represent an opportunity for the port 
of Gioia Tauro to become one of the main gateways of the European Southern Range. Specific measures are envisaged for the simplification and attraction of investments, boosting the development of the port hinterland.

The remaining part of the paper is articulated as follows. Section 2 presents the methodology adopted in the paper. Section 3 reports the current strengths and weaknesses of the port of Gioia Tauro (Italy). Section 4 reports the scenario and the planned transport interventions in Gioia Tauro. Finally, the conclusions and the perspectives.

\section{METHODOLOGY}

The existing methodologies for the identification of the strategic development directions and of planned interventions may be classified into two main categories:

1. methods and models to estimate costs and flows of freight along transport networks; among them, there is the class of Transport Systems Models (TSMs) ([6]-[8]);

2. methods and models to estimate the economic impacts (e.g. value added, employment) generated by existing port operations (e.g. handled freight) and by infrastructure investments (e.g. transport interventions) (see [9], [10]).

As far as concern TSMs, they mainly support the assessment of the transport convenience of using infrastructures and services (e.g. a port), as part of the supply chain for serving the international and domestic trades. TSMs have three components:

- $\quad$ supply (network) models, to assess the performances resulting from users (actors in the freight transport process) and from infrastructures and services;

- travel demand models, to assess users' choices resulting from activities (production, consumption, trade) and infrastructure and service performances;

- assignment models, to assess the mutual interaction between users' choices and infrastructure and service performances.

The outputs of TSMs are:

- transport costs, or performances, in terms of travel times, monetary costs, reliability, and other variables;

- freight flows between generation-attraction areas, expressed in quantities, financial or vehicles units;

- level of congestion of transport infrastructures, defined as the ratio between the current (forecasted) freight flows and current (forecasted) capacity.

According to the structure of the TSMs, the following analysis for the port of Gioia Tauro have been considered in this paper (see also [4], [5], [11], [12]):

- aggregated estimation of current handling capacity of the port, both on the sea-side (docks, quays, etc.) and on the land-side (railway and road last-mile connections, etc.); and identification of critical elements of the existing infrastructures and services (reported in Section 3.1);

- aggregated estimation of current and forecasted freight traffic, both on the sea-side (transhipment container traffic) and to the land-side (imported-exported freight via railway and road) according to existing sources, in order to determine the reference market of the port (reported in Sections 3.2 and 4.1); 
- identification of the strategic development directions and of the planned transport interventions (reported in Section 4.2).

The development direction and the planned interventions for the port of Gioia Tauro aim:

1. to let Gioia Tauro become a logistic node inside the supply chain for the international and domestic trade;

2. to increase the added value of handled freight, supporting the development of the whole economy of Calabria [12].

The planned transport interventions aim to achieve the following objectives:

- $\quad$ strengthen transhipment, increasing the infrastructural sea-side supply to support the activities of settled terminal operators, and to encourage the settlement of new terminal operators;

- $\quad$ support the development of the complementary port-related activities, such as the dry dock and the gateway;

- enhance the combined (ship-to-rail and ship-to-road) transport, operated by large international players in the port hinterland.

\section{GIOIA TAURO: CURRENT SITUATION}

This section is articulated into two parts. The first describes the current infrastructural strengths and weaknesses of the port of Gioia Tauro. The second presents the current volumes and categories of freight traffic interesting the port.

\subsection{Strengths and weaknesses of the infrastructural system}

The port of Gioia Tauro is one of the most important transhipment hubs of container traffic in the Mediterranean basin (Fig. 1).

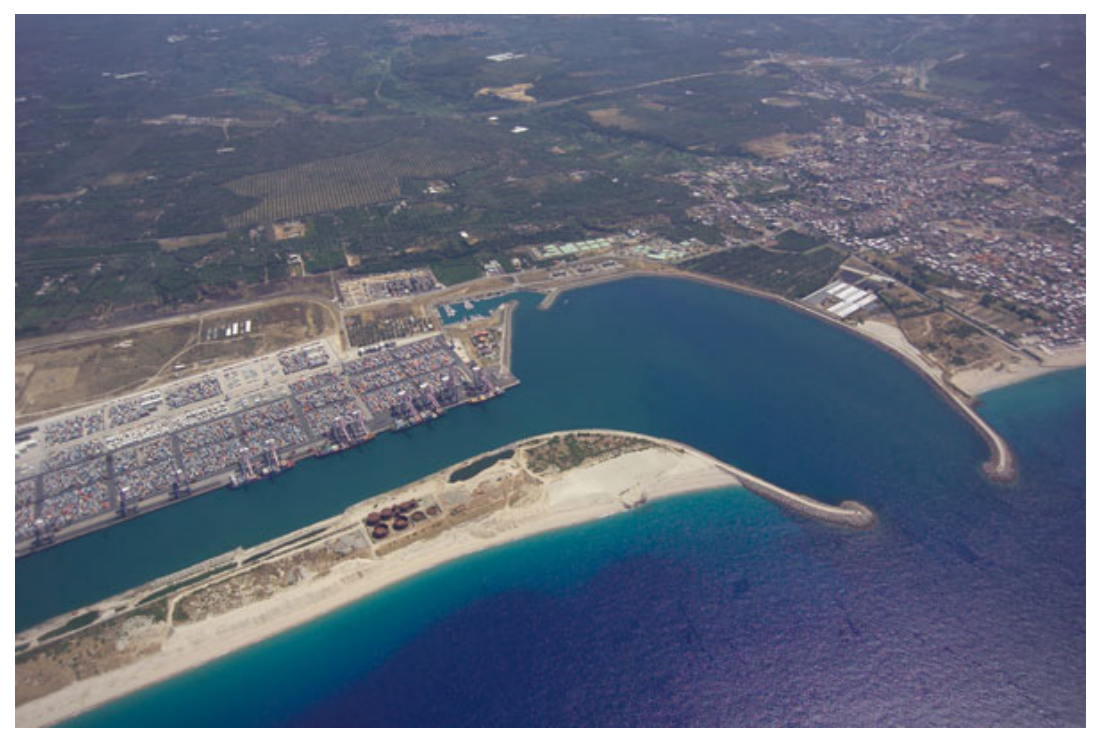

Figure 1: Aerial view of the port of Gioia Tauro. (Source: www.portodigioiatauro.it.) 
The port of Gioia Tauro was built in the 1970s, as part of the special project for the construction of infrastructures in the province of Reggio Calabria (South of Italy). The dimension and the structural characteristics of the port were determined by its original functional destination, serving the industrial settlements planned by the Italian Government, which involved the construction of the $5^{\text {th }}$ Italian Steel Centre in Calabria [11].

The availability of large areas closer to the port docks, the large berths and the high depth of the seabed, allowed Gioia Tauro to be converted from an industrial second-generation port to a potentially third-generation port. In particular, the strong infrastructural equipment made the port of Gioia Tauro a competitive transhipment container port, in relation to other existing ports in the Mediterranean basin. The port of Gioia Tauro started operating as a container port in 1994. The second strength of the port of Gioia Tauro is represented by its advantageous location with respect to the intercontinental maritime routes, crossing the Mediterranean basin form Suez to Gibraltar.

The connection of the port of Gioia Tauro with the Italian and European railway network is an element of weakness. Today the port is connected to the national railway network through the single track and electrified line Rosarno-S. Ferdinando. The line has a double track, but only one is operational, since the terminal section necessary for connection with the Rosarno railway station is missing on the other track.

From the point of view of performance characteristics, the railway network belonging to the national railway company Rete Ferroviaria Italiana (RFI), has a fairly heterogeneous configuration in terms of shape of the tunnels, maximum admitted train lengths and loads.

As regards the shape of the tunnels for combined transport, the Battipaglia (Praia) - Paola, Rosarno-Reggio Calabria, Sibari-Catanzaro Lido and Reggio Calabria lines have a P/C32 shape; while the Paola-Rosarno and Rocca Imperiale - Sibari-S. Antonello - S. Lucido has a $\mathrm{P} / \mathrm{C} 45$ shape.

As regards the maximum axial mass, heterogeneous bounds exist, which are variable from category C3 (with limitations) to category D4 (with limitations) along the most relevant directions. In particular, the entire network is already characterized by category D4 (22.5 ton/axle) with limitations. The Metaponto-Sibari-S.Antonello corridor has an axial mass of category C3 (20 ton/axle) with limitations, while between S. Antonello and S. Lucido the axial mass category is C3 (20 ton/axle). A further element of weakness is represented by the absence of a homogeneous double track layout.

The road connections of the port with the motorway A3 Salerno-Reggio Calabria, that it is subject to an ongoing structural modernization, is need to be maintained in order to allow to increase the level of service.

The above weaknesses regarding railway and road networks, and their last-mile connections with the ports, limit the activities of the port of Gioia Tauro to mere transhipment. The global economic crisis of 2008 and the current one generated by the COVID-19 pandemic revealed the extreme fragility of the single-purpose ports. The port of Gioia Tauro was born and remains mainly a port dedicated to transhipment, its main and characterizing function. The current operational configuration of the port of Gioia Tauro lacks in container traffic originated from local and international firms settled in the Calabria Region.

The planned scenarios and interventions inside the port of Gioia Tauro [11], [12] aim to fully develop its "third-generation" nature. Interventions belong to different classes (material, immaterial, governance, financial), with the objective to reach economic objectives such as traffic maximization, value added, employment. 


\subsection{Current freight traffic}

The port of Gioia Tauro is the first container transhipment port and one of the most important for the automotive sector of Italy ([13]-[15]).

In recent years, the pure transhipment activity of containers recorded a decrease in Italian ports, included Gioia Tauro, mainly determined by the activity termination of Taranto and by the strong competition of ports located in other Mediterranean countries: Greece, Spain, Malta and North Africa (in particular the ports of Port Said and Tanger). As a consequence, in the period 2005-2013 in which traffic in the Mediterranean grew with an annual rate of $6.5 \%$, the Italian ports of Gioia Tauro, Cagliari and Taranto dropped in the market share from $32 \%$ in 2005 to $17 \%$ in 2013 . The container traffic of the port of Gioia Tauro decreased of about $19 \%$ in 2011, if compared to 2010. This was due to the abandonment of the port by the Danish Maersk, who handled about a quarter of all port container traffic and who moved to Port Said and Tanger Med. The year 2019 was characterized for a growth in container traffic up to 2.55 million of TEUs, due to the full acquisition of the terminal by MSC. In 2020 the port of Gioia Tauro was one of the few ports that increased the container traffic, $+26 \%$, respect to 2019. Fig. 2 reports the yearly container traffic in the port of Gioia Tauro from 2001 to 2020.

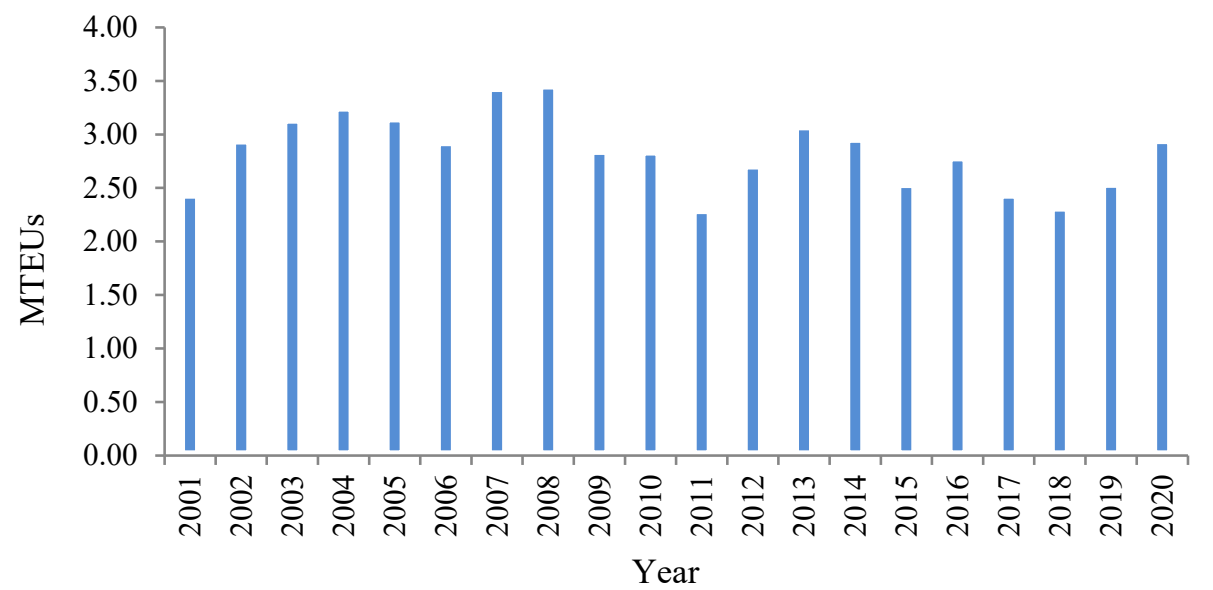

Figure 2: Container traffic in Gioia Tauro port (lift-on/-lift-off services). Years 2001-2020.

As regards the import/export traffic of vehicles operated with roll-on/roll-off services (see Fig. 3), the volumes were respectively about 0.28 and 0.21 millions of vehicles in 2018 and 2019. In general, the historical data show an increasing trend, after the fall observed in years 2015-2016.

The international freight transport that involves the port of Gioia Tauro exclusively concerns maritime container transport via transhipment. The amount of containerized freight imported/exported through Gioia Tauro via road and rail transport was negligible in the last years. Until 2008 twenty block-trains every week departed from Gioia Tauro, through the railway station of Rosarno, towards the terminals of Nola (Naples), Bari, Frosinone, Padua, Melzo (Milan), Bologna and La Spezia. Afterwards, due to competitiveness loss of the 


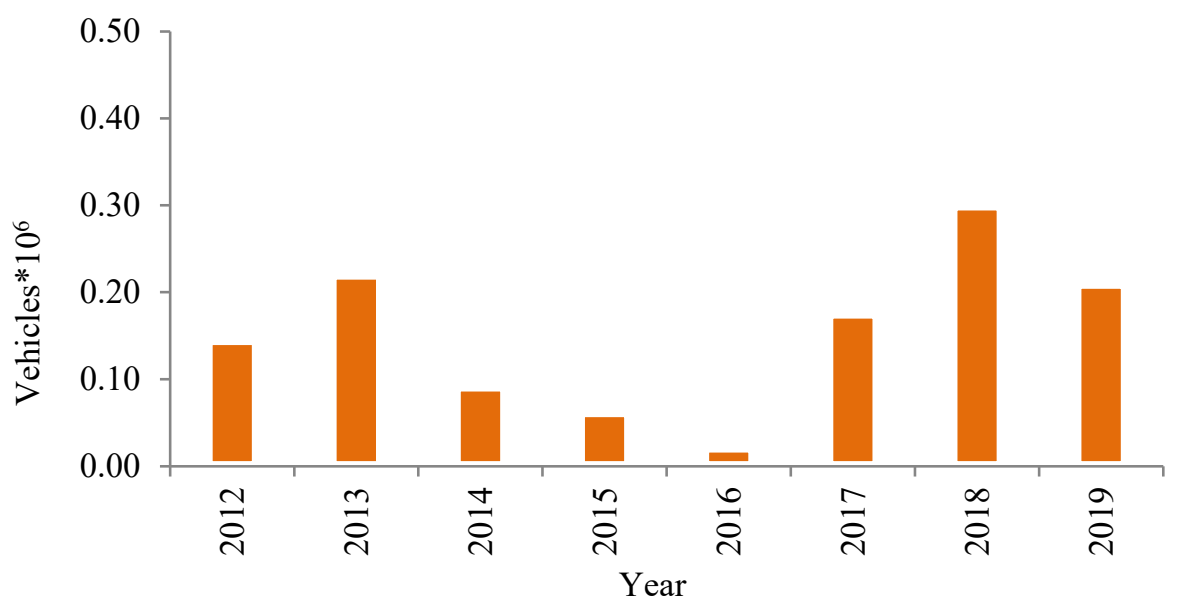

Figure 3: Vehicles handled in Gioia Tauro with international roll-on/-roll-off services. Years 2012-2019.

railway system compared to the road system and the abandon of the port by Maersk, the rail services were totally cancelled. Last year railway services were again activated after the opening of the gateway.

\section{GIOIA TAURO: DEVELOPMENT DIRECTIONS AND INTERVENTIONS}

\subsection{Strategic development directions}

Some forecasts indicate a number of containers handled between 78 (instability case) and 84 million TEU (recovery case) at 2025 in the Mediterranean basin [16].

This rich container market concerning the Euro-Mediterranean region, mostly served by lift-on/lift-off services, is contested between the ports of the European Northern Range and the ports of the Mediterranean. Furthermore, there is a strong competition between the ports of the Mediterranean due to the birth of new ports and the expansion of the existing ones.

Furthermore, there are significant exchanges of freight inside the Mediterranean Basin between the countries of the Northern-Mediterranean shore with those (MENA Region) of the Southern-Mediterranean shore, operated mainly through roll-on/-roll-off services.

The role of roads and railways infrastructures of Italian and European interest is decisive in ensuring accessibility and exchanges between Calabria and the rest of Italy, and Europe. Most of the freight traffic involving Italy relates to the North-South route, and in particular Germany. In this perspective, Europe has defined the TEN-T (Trans European Network Transport) infrastructural networks and corridors, and the RFC (Rail Freight Corridors) corridors.

Therefore, the infrastructural interventions planned inside the strategic report of the ALI of Gioia Tauro [12] aims to guarantee the connection of Calabria, and of the port of Gioia Tauro as core port, to the European road and railway networks. The planned interventions represent an opportunity for the port of Gioia Tauro to become one of the main gateways of the South European Range. They aim to pursue the objectives and the Italian and European 
targets concerning the freight mobility, such as the shift from road to rail of $30 \%$ of freight by 2030 and of $50 \%$ by 2050 (see [4], [5]).

\subsection{Planned general interventions}

The general interventions are composed of two categories of interventions, aimed to (see Table 1):

1. the expansion of the port infrastructure (sea-side), and

2. the increase of the railway and road infrastructure (land-side).

Table 1: Planned interventions for general logistics in the port of Gioia Tauro.

\section{Seaside}

Building the quay of the southern evolution circle

Building the quay extension of the southern evolution circle

Completion of the western quay on the northern side (beach closure)

Dry dock: industrial facilities

Dry dock: civil works

Land side: railway

Upgrading of last-mile railway connections in the port area

Upgrading to the standard of 750 meters of the San Ferdinando railway checkpoint

Building railway tracks serving the industrial area

Upgrading the railway track serving the cold-pole inside the industrial area

Upgrading to the standard of 750 meters of the Rosarno-Paola-Sibari section

Second railway track: electrification and updating to the standard of 750 meters

Last-mile railway track for southern connection to TEN-T network

Land side: road

Road link for the southern connection between the port and the TEN-T network

Road link between the Rosarno junction of A2-Motorway and the port gate (East side)

Increasing the level of service of the Rosarno junction of A2-Motorway

Functional enhancement of existing service road inside the industrial area

Construction of a new service road inside the industrial area

Figs 4 and 5 show respectively the planned road and railway infrastructures and the industrial area located the hinterland of the port of Gioia Tauro.

The planned interventions related to smart town, research and development, agri-food and mechanical logistics are respectively proposed in [17]-[20]. 


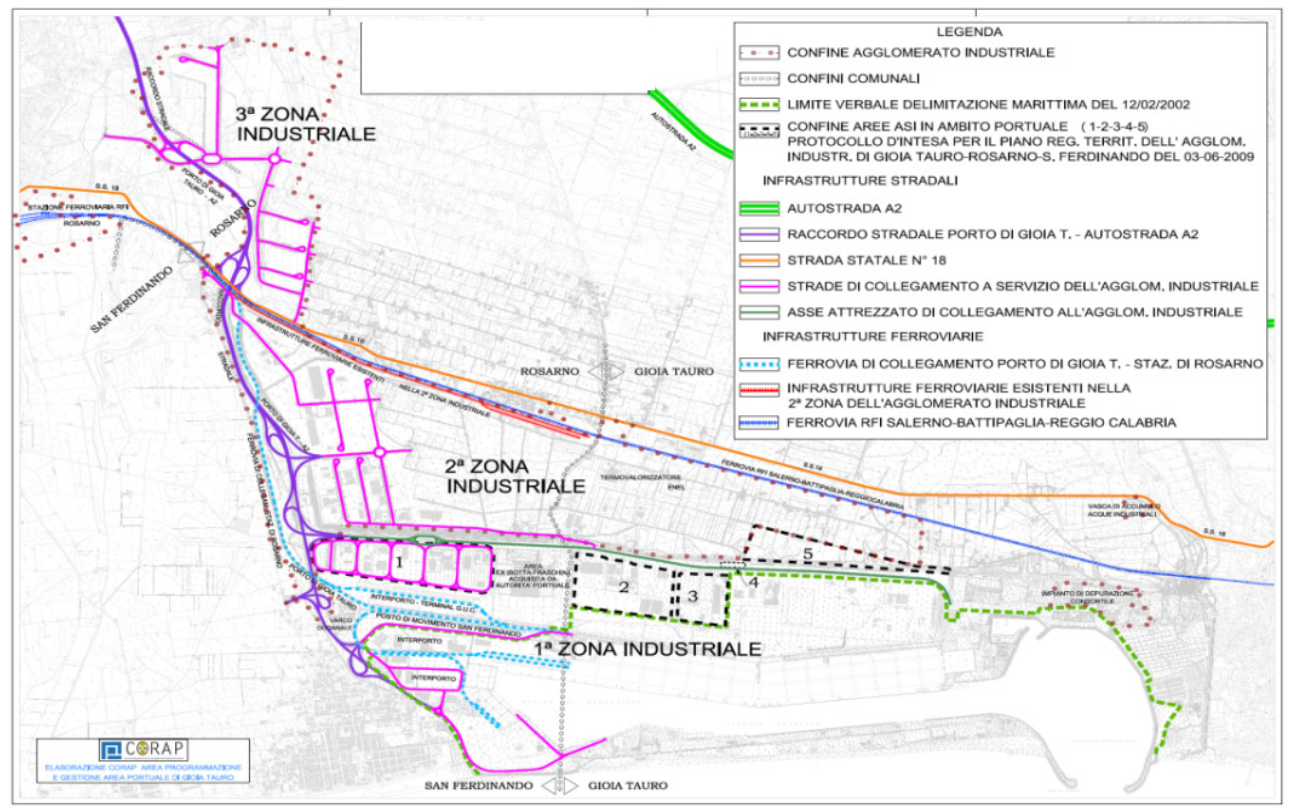

Figure 4: Planned road and railway infrastructures in port of Gioia Tauro [11], [12].

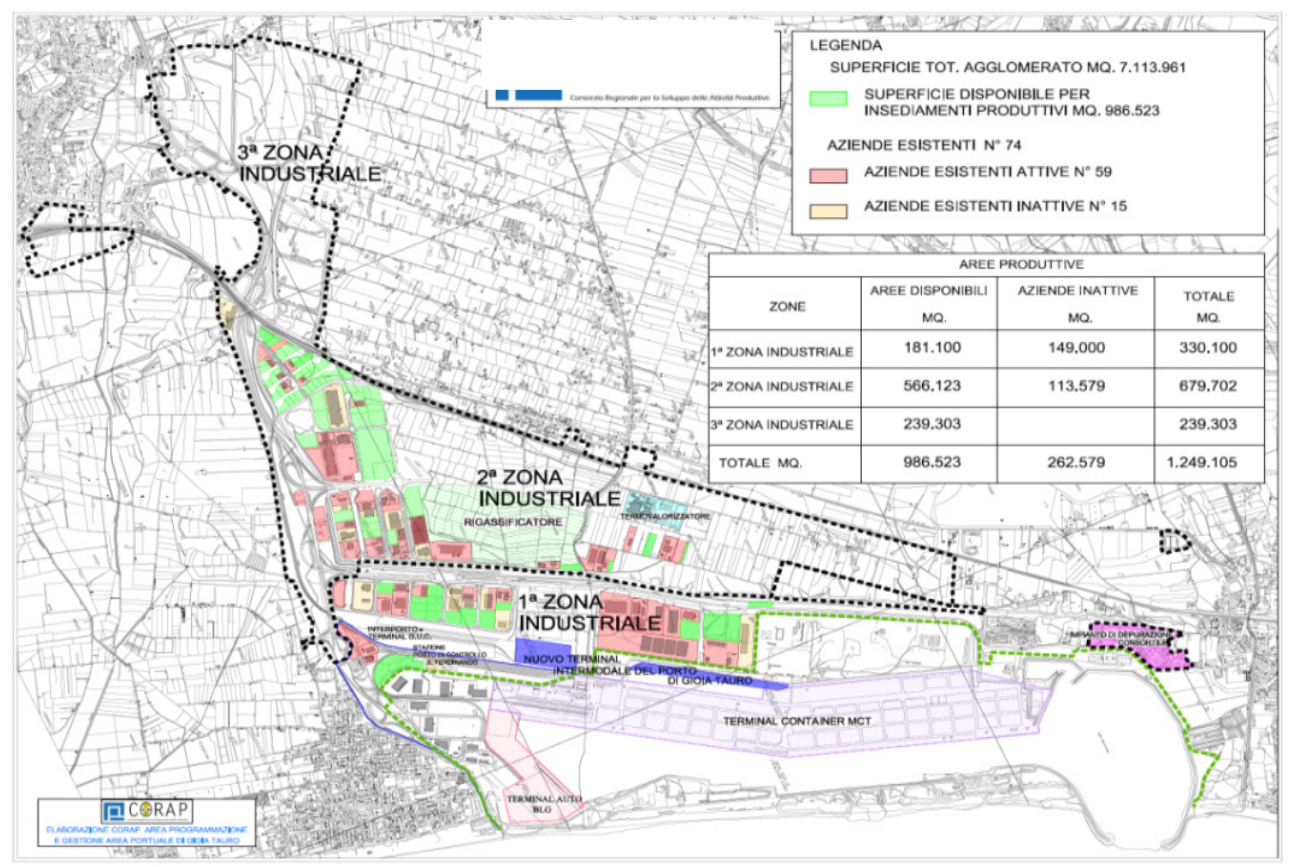

Figure 5: Industrial area in the port of Gioia Tauro [11], [12]. 


\subsubsection{Sea-side infrastructures}

The main planned interventions on the seaside are reported below:

- Building the quay of the southern evolution circle:

- construction of the southern quay by re-profiling the quay of the evolution basin, in order to avoid interference between the ships that dock and the ships that manoeuvre inside the evolution circle of the port basin;

- expand the supply for port operators in the southern area of the port;

- construction of a new terminal for the potential settlement of additional operators, by the acquisition of new spaces close to the port quays.

- Building the quay extension of the southern evolution circle:

- acquisition of new areas through expropriations;

- construction of the yards;

- extension of the southern quay;

$\circ$ building service roads for the movement of vehicles.

- Completion of the western quay on the northern side:

- construction of quay in the current area, where it is present a "beach",

- completion of the infrastructure in the western part of the canal.

- Dry dock: industrial facilities: purchase of a floating dry dock.

- Dry dock: civil works: resection of the western quay for the installation of the floating dry dock.

\subsubsection{Land-side infrastructures}

The main interventions on the land-side are planned to strength the rail and road last-mile connections of the port to the TEN-T networks.

a. Railway

- $\quad$ Upgrading of last-mile railway connections in the port area:

$\circ$ updating of the railway links between the San Ferdinando checkpoint and the TIL tracks;

- updating of the railway links to the Automar tracks bundle.

- Upgrading of the San Ferdinando checkpoint to the standard of 750 meters.

- Building railway tracks serving the industrial area: building railway track serving the portion of industrial area closer to the port yards from the San Ferdinando checkpoint.

- Upgrading the railway track serving the cold-pole inside the industrial area: upgrading of the last-mile railway connection of the cold-pole (warehouses) located in the industrial area to the TEN-T railway network.

- Upgrading to the standard of 750 meters of the Rosarno-Paola-Sibari section.

- Second railway track: electrification and updating to the standard of 750 meters, Increasing the performance of the railway infrastructure serving the gateway, with the aim to increase the last-mile connections of the port to the TEN-T railway network.

- Last-mile railway track for southern connection to TEN-T network: construction of a southern connection (single track) between the port of Gioia Tauro and the TEN$\mathrm{T}$ network, in order to ensure a direct connection for freight arriving/departing from/to the city of Reggio Calabria and Sicily. 
b. Road

- Road link for the southern connection between the port and the TEN-T network: construction of a road link between the Gioia Tauro junction of the A2 Motorway and the port, in order to ensure a direct connection for people and freight arriving/departing from/to the city of Reggio Calabria and Sicily.

- Road link between the Rosarno junction of A2 Motorway and the port gate (East side): functional enhancement of the road link between the junction of Rosarno of A2 motorway and the port gate (East side).

- Increasing the level of service of the Rosarno junction of A2-Motorway: road works aimed at increasing the level of service level the Rosarno junction of A2-Motorway

- Functional enhancement of existing service road inside the industrial area:

- functional enhancement of the existing service road axis inside the industrial area, in order to increase the connection of the industrial area with the port and the A2 motorway,

- functional enhancement of the extension of service road, with a specific attention to the section close to the custom gate,

$\circ$ upgrading the yards in front of the custom gate,

$\circ$ building of a car-parking area and of a road link with the town of San Ferdinando.

- Construction of a new service road inside the industrial area: construction of a new service to serve the industrial area, in order to increase accessibility for heavy vehicles.

\section{CONCLUSIONS}

The port of Gioia Tauro is one of the main commercial ports in Italy, specialized in container transhipment operations of freight at international level [9].

The paper presents an analysis of current conditions of the port of Gioia Tauro, in the context of Calabria Region. Then, scenarios and planned interventions towards the third generation for Gioia Tauro are proposed, with a focus on general logistics. The scenarios and interventions are defined inside the Regional Transport Plan of Calabria [11] and in the strategic report for the ALI of Gioia Tauro [12].

Some conclusions regarding the methodology and the results obtained are reported below.

The methodology is derived from the TSM approach, that conceptually focuses on the analysis of the three components of a transport system: the supply (freight infrastructures and services performances), the demand (freight flows), and supply-demand interaction (level of congestion). The presented methodology is suitable to be applied in other ports, that are experimenting a similar evolution towards the third-generation nature.

The planned transport interventions in the port of Gioia Tauro are identified, according to the methodology defined in Section 2, in order to ensure the high level-of-service standards of the sea-side and land side infrastructures.

As far as concerns the sea-side port infrastructures, the planned interventions will allow:

- to maintain the level of service of the quays and yards to the standards required by the container and ro-ro terminal operators;

- to increase the capacity of the port in order to receive and handle last-generation container and ro-ro ships;

- to allow the settlement of further operators in the port. 
According to aggregated estimates of sea-side port capacity and to the maritime freight flow forecasts, both for container and ro-ro services in the Mediterranean Sea, the above seaside transport interventions will increase the transhipment handling capacity of the port by at least 1 million of TEUs; the capacity of the deep sea e ro-ro services of at least 100,000 cars, and the capacity of the short-sea ro-ro service of 200,000 trucks of articulated lorries (see [4], [5]).

As far as concerns the land-side port infrastructures, the planned interventions will allow:

- the composition of trains of 750 meters, which is the current standard in Europe, allowing to reduce the travel cost on the railway mode;

- the improvement and the realization of the road last-mile connections between the port and the Italian A2 Motorway; thus, incrementing the accessibility to the domestic freight production areas and consumption markets.

The planned transport interventions aim to achieve the objectives to strength of transhipment activities, to support the development of further port-related activities, such as combined transport, with the goal to increase the level of integration of the port of Gioia Tauro in the international and domestic supply chains (third-generation port), and to ensure the growth of the whole Calabria Region. After the realization of the planned interventions, it is foreseen the execution of an ex-post validation of the results obtained.

\section{REFERENCES}

[1] UNCTAD Secretariat, Port Marketing and the Challenge of the Third Generation Port, UNCTAD Secretariat, 1994.

[2] UNCTAD Secretariat, Report by the secretariat of the United Nations Conference on Trade and Development, New York and Geneva, 1999.

[3] Russo, F. \& Musolino, G., Quantitative characteristics for port generations: The Italian case study. International Journal on Transport Development and Integration, 4(2), pp. 103-112, 2020. DOI: 10.2495/TDI-V4-N2-103-112.

[4] Russo, F. \& Chilà, G., Structural factors for a third-generation port: Current state, limits and weaknesses of Gioia Tauro, Italy, in the regional transport plan. WIT Transactions on the Built Environment, vol. 204, 2021, accepted for publication, WIT Press, ISSN 1743-3509.

[5] Russo, F. \& Chilà, G. Structural factors for a third-generation port: Actions and measures for Gioia Tauro in the regional transport plan. WIT Transactions on the Built Environment, vol. 204, 2021, accepted for publication, WIT Press, ISSN 1743-3509.

[6] Cascetta, E., Transportation Systems Analysis. Models and Applications, SpringerVerlag: New York, 2009.

[7] Ben-Akiva, M., Meersman, H. \& Van de Voorde, E. (eds), Freight Transport Modelling, Emerald, 2013.

[8] Tavasszy, L. \& de Jong, G. (eds), Modelling Freight Transport, Elsevier Inc., 2014.

[9] Cascetta, E., Nuzzolo, A., Biggiero, L. \& Russo, F. Passenger and freight demand models for the Italian transportation system. Proceedings of 7 th World Conference on Transport Research, Volume 2: Modelling Transport Systems, Elsevier, 1996.

[10] Russo, F. \& Musolino, G., A unifying modelling framework to simulate the Spatial Economic Transport Interaction process at urban and national scales. Journal of Transport Geography, 24, pp. 189-197, 2012.

[11] Regione Calabria, Piano Regionale dei Trasporti, Regione Calabria: Catanzaro, 2016. 
[12] Ministero Infrastrutture e Trasporti, Area Logistica Integrata del Polo di Gioia Tauro: Documento di Sviluppo e di proposte. PON Infrastrutture e Reti 2014-2020. Roma, Italia, 2018.

[13] Russo, F. \& Musolino, G., Estimating demand variables of maritime container transport: An aggregate procedure for the Mediterranean area. Research in Transportation Economics, 42, pp. 38-49, 2013.

[14] Russo, F., Musolino, G. \& Assumma, V., An integrated procedure to estimate demand flows of maritime container transport at international scale. International Journal of Shipping and Transport Logistics, 6(2), 2014.

[15] Russo, F. \& Musolino, G., Geographic factors affecting the presence of transhipment services in regional maritime container markets. Geographical Analysis, 45, pp. 90 102, 2013.

[16] Drewry, Annual Review and Forecast 2020/21. https://www.drewry.co.uk, 2020.

[17] Russo, F., Panuccio, P. \& Rindone, C., Structural factors for a third-generation port: Between hinterland regeneration and smart town in Gioia Tauro. WIT Transactions on the Built Environment, vol. 204, 2021, accepted for publication, WIT Press, ISSN 1743-3509.

[18] Russo, F. \& Rindone, C., Structural factors for a third-generation port: Planning interventions for research and development in Gioia Tauro TEN-T node. WIT Transactions on the Built Environment, vol. 204, 2021, accepted for publication, WIT Press, ISSN 1743-3509.

[19] Musolino, G. \& Trecozzi, M. R., Structural factors for a third-generation port: Planning interventions for agri-food logistics in Gioia Tauro, WIT Transactions on the Built Environment, vol. 204, 2021, accepted for publication, WIT Press, ISSN 1743-3509.

[20] Musolino, G., Cartisano, A. \& Fortugno, G., Structural factors for a third-generation port: Planning interventions for mechanical logistics in Gioia Tauro. WIT Transactions on the Built Environment, vol. 204, 2021, accepted for publication, WIT Press, ISSN 1743-3509. 